\title{
El porvenir de una colección. Cultura burguesa, identidad y memoria pública a través del Museo Municipal de Arte Decorativo "Firma y Odilo Estévez" de Rosario
}

RMA

Museología

\begin{abstract}
Leonardo C. Simonetta* y Horacio Miguel Hernán Zapata**
* Escuela de Historia y Centro Interdisciplinario de Estudios Sociales, Facultad de Humanidades y Artes, Universidad Nacional de Rosario, Centro Documental "Ruben Naranjo", Museo de la Memoria de Rosario. E-mail: leosimonetta@hotmail.com; ** Nodo CESOR, Red ISHiR-CONICET, Escuela de Historia y Centro Interdisciplinario de Estudios Sociales, Facultad de Humanidades y Artes, Universidad Nacional de Rosario, Sección Etnohistoria, Instituto de Ciencias Antropológicas, Universidad de Buenos Aires. E-mail: horazapatajotinsky@hotmail.com
\end{abstract}

\section{Resumen}

El artículo reconstruye, apelando a un enfoque que conjuga los aportes de la historia social, la historia cultural y los estudios museológicos sobre patrimonio, el derrotero de una colección privada de arte reunida por el matrimonio conformado por Firma Mayor y Odilo Estévez Yáñez, dos integrantes del grupo social dominante que sentó las bases para la construcción de un orden burgués en la ciudad de Rosario a principios del siglo XX. Estudia además el papel central que jugó -y aún juega- este acervo, por un lado, en la creación de uno de los principales museos que existen actualmente en la localidad, el Museo Municipal de Arte Decorativo "Firma y Odilo Estévez"; y, por el otro, en la configuración de la identidad y memoria pública de estos coleccionistas que los perpetuarán como figuras destacadas del pasado local en el imaginario institucional y colectivo a través de los objetos que alguna vez les pertenecieron.

Palabras clave: burguesía local; identidad; memoria pública; museo de arte; patrimonio; Rosario

The future of a Collection. Bourgeois culture, identity, and public memory through the Museo Municipal de Arte Decorativo "Firma y Odilo Estévez" of Rosario city

\begin{abstract}
The article reconstructs the history of a private art collection gathered by Firma Mayor and Odilo Estévez Yánez, a married couple from the dominant social group that laid the foundations for the construction of a bourgeois order in the city of Rosario at the beginning of the 20th century. This reconstruction is undertaken from an approach that combines the contributions of social history, cultural history and museological studies on heritage. The essay also studies the central role that this collection has played, on the one hand, in the creation of one of the major museums in Rosario today, Museo Municipal de Arte Decorativo "Firma y Odilo Estévez"; and, on the other hand, in the configuration of these collectors' cultural identity and public memory, perpetuated as prominent people of the local past in the institutional and collective consciousness.
\end{abstract}

Key Words: local bourgeoisie; identity; public memory; art museum; heritage; Rosario city

El coleccionista sueña con un mundo lejano y pasado, que además es un mundo mejor en el que los hombres están desprovistos de lo que necesitan como en el de cada día, pero en cambio las cosas así están libres en él de la servidumbre de ser útiles

Walter Benjamin (1987 [1937])

\section{A modo de introducción}

Ver en la actualidad el Museo Municipal de Arte Decorativo "Firma y Odilo Estévez" de la ciudad de Rosario, recorrer sus múltiples salas, con sus paredes y ambientes engalanados con obras de arte de diversas épocas y procedencias, produce sentimientos diversos. Pero por sobre todo, causa asombro el solo hecho de pensar que en esas enormes habitaciones

Recibido 05-05-2011. Recibido con correcciones 21-03-2012. Aceptado 24-04-2012 
profusamente decoradas trascurrieron los días de un solitario matrimonio, integrado por Odilo Estévez Yáñez (1870-1944) y Firma Mayor (1874-1964), y de tan sólo algunos empleados domésticos; que el actual edificio de este museo era, en su momento, el escenario concreto en el que se desenvolvía la cotidianeidad particular de un hogar típicamente burgués de principios del siglo XX, signada por prácticas de sociabilidad de la más diversa índole: desde el acostumbrado ritual de la visita a las siempre convenidas reuniones de negocios, y desde las cenas inter-pares a los encuentros de las damas encargadas de coser la bandera que se elevaría en el mástil del entonces recién creado Monumento Nacional a la Bandera.

Frente a este pasado de la casa y de la familia que en ella habitó, pero también de cara al presente materializado en los objetos allí contenidos, se ha creado y recreado una memoria pública particular presente en la ciudad de Rosario. Este fenómeno social y simbólico se explica, en parte, por los diferentes móviles que concurrieron y motivaron, desde un principio, la creación del Museo Municipal de Arte Decorativo "Firma y Odilo Estévez". En principio se deben considerar las expectativas relacionadas a cómo este tipo de instituciones públicas, los museos, incidirían en la imagen positiva que la ciudad de Rosario proyectaba al resto del país, propósito que era insistentemente buscado por la burguesía rosarina desde la década de 1910. Es que la sola existencia de entidades abocadas a la conservación, protección y difusión del patrimonio cultural y artístico constituía una muestra palpable del grado de civilización alcanzado por la ciudad y, más particularmente, del rol activo de su burguesía en la consecución de ese enaltecimiento intelectual. Por eso es que el Museo Municipal de Arte Decorativo "Firma y Odilo Estévez" debe enmarcarse en un proyecto de más alto alcance, que visualizaba tanto un perfil definido en términos artísticos como la proyección del acervo privado en el dominio público, lo que suponía dotar a la ciudad de Rosario de las manifestaciones culturales faltantes y sostener un ánimo de trascendencia personal corporizado en el destino proyectado sobre sus colecciones, en plena conciencia de que éstas debían superar los conspicuos límites impuestos por el ámbito privado para adquirir un ribete público. Por supuesto que la existencia de museos no sólo ayudaba a tornar una realidad esta premisa, sino que también -y sobre todo- legitimaba la preeminencia de aquellos miembros de la clase burguesa que gustaban ser reconocidos como la elite.

También existen razones de índole específica, no menos importantes, que explican por qué la presencia de este acervo privado de objetos de arte e historia coleccionados por este matrimonio, integrante del grupo social dominante que sentó las bases para la construcción de un orden burgués en la ciudad a principios del siglo $\mathrm{XX}$, aún juega un papel central en el tejido de la memoria de los rosarinos. El hecho mismo de que el Museo se constituyera, de alguna manera, en una herramienta pedagógica que sintetizaba -a través de la vida de Firma y Odilo Estévez- el origen de la ciudad de Rosario, las principales características de su población y, en definitiva, su misma trayectoria histórica como sociedad, agregaba un plus de valor a su nacimiento $y$, sobre todo, a su consolidación en la esfera pública. Es por esto que la presunción por parte del municipio de Rosario de que la donación de esta casa, que albergaba una colección de objetos de suma importancia artística e histórica, y su transformación ulterior en un "lugar de memoria" representativo de la idiosincrasia local ha contribuido a delinear una narrativa que invoca -todavía en el presentea estos coleccionistas burgueses como figuras destacadas del pasado local.

Teniendo en mente el conjunto de cuestiones anteriormente reseñadas que resultan de la emergencia este museo rosarino y de un imaginario social particular ligado a éste, el objetivo del presente artículo se orienta básicamente en dos direcciones: por un lado, indagar el derrotero del acervo patrimonial privado, deteniéndose específicamente en aquellos caracteres que se vinculan con las modalidades y mecanismos de adquisición puestos en juego por la pareja, los diacríticos identitarios presentes en las elecciones y los intentos de la burguesía por legitimar su preeminencia social; y por otro, analizar los procesos políticos, materiales, culturales y simbólicos que intervinieron activamente en la configuración de representaciones vinculados a la colección y al rol del matrimonio Estévez-Mayor como burgueses coleccionistas. Para ello se apela a un enfoque analítico que conjuga los aportes de la historia social, la historia cultural y los estudios museológicos sobre patrimonio.

\section{Un contexto para la colección Estévez-Mayor: Rosario y su burguesía}

Por lo general, en el recuerdo de la sociedad rosarina, los nombres de Firma Mayor y Odilo Estévez aluden a la vida de dos personas que, como muchas otras, no sólo participaron de las expectativas de crecimiento de la ciudad de Rosario y su hinterland productivo que se dieron desde la segunda mitad del siglo XIX, sino también de la propia afirmación de su trama urbana e importancia demográfica en el plano nacional en general y en la región pampeana en particular. Una ciudad que, huérfana de padres fundadores y de fecha de nacimiento, reconocía su pujanza social y económica en su forma particular de inserción dentro de la estructura capitalista del modelo agroexportador que se fue imponiendo: la propia del comercio y de la industria.

En efecto, desde que la antigua villa del Pago de los Arroyos funcionó como el único puerto ultramarino de la Confederación Argentina (1853-1860), es decir, como núcleo de intermediación entre el mercado internacional y los espacios regionales del interior argentino, el paisaje 
local se vio modificado con el consecuente incremento de la oferta de servicios urbanos, las comunicaciones (empresas de transportes terrestres y fluviales), el comercio y la población (Videla y Fernández 2001: 62-63). En las décadas subsiguientes a la apertura de los ríos al comercio internacional (1860-1870), la provincia de Santa Fe se transformó en un escenario de oportunidades, una verdadera frontera abierta donde varios empresarios, comerciantes, ganaderos y antiguos propietarios de tierras se involucraron en una amplia oferta de rubros en los que invertir capital resultaba altamente provechoso a la vez que rentable (Bonaudo 2006b: 57-60): en primer lugar, la colonización privada de tierras destinadas a la producción agraria (Gallo 2004 [1983]; Bonaudo 2006a); en segundo lugar, las inversiones en la infraestructura necesaria (ferrocarriles, puertos) para transportar la producción del $80 \%$ de las tierras dedicadas al cultivo de cereales hacia Rosario y desde allí nuevamente para ser distribuida a los mercados ultramarinos y las provincias del interior del país (Bonaudo 2006b: 79-80); y en tercer lugar, el establecimiento de una densa red de servicios de intermediación, instituciones financieras y de negocios (Frid 2007, 2008).

A resultas de esto, el papel de la ciudad en el ámbito regional fue central. Rosario se transformó en el centro neurálgico del sur de la provincia de Santa Fe, liderando la actividad comercial vinculada a la exportación agrícola y a los vastos sectores mercantiles y bursátiles: consignatarios de cereales, rematadores y representantes de casas exportadoras de granos de Buenos Aires, prestamistas, bancarios y accionistas de la bolsa con intereses en esta rama. El desenvolvimiento de las actividades fabriles en la ciudad fue la otra cara de la expansión agraria, signado por el desarrollo de talleres del ferrocarril, las empresas ferroviarias y las industrias instaladas en el espacio urbano (como las refinerías, fundiciones, herrerías mecánicas y entidades dedicadas a la fabricación de harinas, de maquinaria agrícola, ladrillos, bolsas, equipos para molinos y cervezas) (Fernández 1999; Frid 2008, Pons y Ruiz 2006).

No obstante, el largo ciclo de prosperidad impulsado por la exportación agraria recibió primero el golpe de la crisis internacional de 1913 y el de la llamada Gran Guerra (1914-1918) después, lo que clausuró las favorables condiciones que había provisto la agricultura pampeana hasta entonces. No obstante, la lenta recuperación productiva que siguió a la crisis de posguerra y el alza de la demanda de cereales que alentó el crecimiento de la economía argentina hicieron que la década de 1920 fuera una de las coyunturas de mayor esplendor para la ciudad de Rosario, que miraba con beneplácito los nuevos bríos que tomaban tanto el mercado agrícola de la zona como el incremento del consumo a partir del aumento de la demanda local y regional. Por su parte, la crisis mundial de 1930 vendría nuevamente a ensombrecer la recuperación del período anterior. En efecto, la caída de los precios agrícolas y ganaderos puso fin al patrón de crecimiento cimentado en la expansión de la demanda internacional de los productos derivados de la actividad agroexportadora. Frente a la caída de la actividad portuaria, que impactó fuertemente en los emprendimientos comerciales y financieros ligados a ésta, Rosario debió ceder su liderazgo a Buenos Aires en la importación de cargas, por un lado, y concentrarse paulatinamente en la exportación de granos, por otro (Sonzogni et al. 1987; Videla y Fernández 2001). Pese a ello, la crisis abrió otras expectativas y caminos a futuro, puesto que tras haber dejado en ruinas aquellas actividades fabriles tradicionales, obligó a relocalizar varios establecimientos y reconvertir el eje de la industria y los negocios del área. Fue así que la importante base industrial que Rosario poseía y la cuantiosa oferta de mano de obra, tanto industrial especializada como aquella no especializada producto de la crisis, incentivaron el desarrollo de la industria pesada (metalmecánica, petroquímica y papelera), situadas en el gran área metropolitana de la ciudad (Frid 2008).

La transformación radical en la economía y la reorganización productiva y material del espacio urbano de Rosario estuvieron acompañados también por cambios demográficos y culturales que contribuyeron a que la sociedad adquiera nuevos ribetes y complejizara su dinámica. Es claro que el grupo que más se benefició de esta etapa fue aquel compuesto por ganaderos, empresarios y comerciantes. Con todo, su maduración y construcción como la clase social dominante local fue paulatina, a punto tal que recién hacia principios del siglo XX sí es pertinente -siguiendo siempre las investigaciones más convincentes- definir con ese rótulo a los sectores más importantes a nivel económico y social de la ciudad. Una de las notas más significativas de esta futura burguesía de Rosario fue su origen inmigratorio y la bonanza alcanzada a través de las actividades empresariales y mercantiles en el ámbito regional. En efecto, a diferencia de sus pares de Buenos Aires y de otras ciudades del interior del país, los grupos burgueses locales poco debían su éxito al pasado colonial o a la experiencia criolla de la primera mitad del siglo XIX (Megías 1996). Y ello fue así debido a que la inmigración europea, principalmente de origen italiano y español, proveyó buena parte del elenco de hombres que supieron aprovechar las ventajas de actuar como un grupo diversificado en la inversión inmobiliaria urbana y rural, la explotación agropecuaria y el comercio exportador e importador de comestibles, maquinaria agrícola y de bienes de consumo (Pons y Videla 2005; Frid 2006; Lanciotti 2009). Fue esta nómina estable de comerciantes, empresarios y profesionales notables la que conformó el núcleo principal del influyente sector de Rosario que, a través de una densa red de relaciones y solidaridades (basadas en vínculos de parentesco, paisanaje y colaboración profesional), lograron insertarse exitosamente en los principales espacios de la vida económica, social e institucional de la ciudad (Frid de Silverstein 1993; 1994; Fernández, Pons y Videla 1999-2000). 
De todos modos, el alto status conseguido por la burguesía rosarina tuvo su otro indicador más contundente en el hecho de que, entre los últimos años del siglo XIX y los primeros del $\mathrm{XX}$, sus comportamientos y usos sociales buscaran ser tomados como sinónimos de distinción. No obstante, dicha necesidad tomó vigor en un contexto en el que la noción de "patriciado" y la antigüedad familiar como fuente de legitimidad adquirieron una importancia política y simbólica sumamente notable (Losada 2008: 313-364, 2009: 190-195). Semejante relevancia no fue casual en tanto se hacía referencia a un actor colectivo vinculado a las familias que, cualquiera fuera su origen (de vieja raigambre colonial, protagonistas de la revolución de independencia o impulsoras de la modernización económica y la organización institucional de mediados del XIX), encontrándose en aquel momento con las riendas del poder, habían sabido construir a la Argentina como país, entendida esta tarea en un sentido bastante laxo. Esta noción que alimentaba el proyecto político hegemónico en el cambio de siglo, dejaba entonces fuera no sólo a Rosario sino también a sus grupos dirigentes, cuya principal proclama pasaba por subrayar sus credenciales no basadas en los privilegios de la cuna sino en el mérito y la virtud cultivados en la "ciudad que se hizo a sí misma" a partir de su alta matriz inmigratoria, de sus éxitos en los negocios y de un progreso moral e intelectual nunca bien ponderado.

Tratando de romper las imágenes levantadas por las elites porteñas con respecto a la ciudad -y que aludían sobremanera a aquella trama social heterogénea y asentada en el desempeño y en los logros individuales, particularmente procurados por la actividad mercantil de sus miembros más notorios- como por ejemplo la Chicago argentina, sus más noveles pares rosarinos alentaron el despliegue de expresiones vinculadas a la escala axiológica del orden burgués que aceleradamente se iba consolidando. Más allá de la convivialidad con la "alta sociedad" de la cercana Buenos Aires -y de los estilos que aspiraban a cultivar, más no siempre a reproducir-, la burguesía rosarina inauguró propuso nuevos giros para varios de los proyectos de modernización de la ciudad en el espacio público local (Fernández 2003; 2007).

Dentro de estas coordenadas, la burguesía local buscó dotar a la sociedad de Rosario de un barniz de prestigio y de alta estatura sociocultural en el marco de una sociedad de masas que emerge en los años de entreguerra. Y lo hizo a partir de un modelo que, enarbolado sobre referencias culturales aristocráticas europeas, asentaba la preeminencia pública en criterios diversos como el buen gusto (manifestado en un consumo suntuario marcado por la sofisticación en los cánones estéticos), el refinamiento de las formas de vida (en un sentido parecido al autocontrol emocional) y la exaltación de virtudes y valores propios del civismo republicano (a través de la creación de un museo cívico, etnográfico e histórico y la realización de conciertos, galas literarias, conferencias y muestras artísticas). Como parte de ese programa, el consumo cultural y ostentoso emergió con fuerza, amplió sus horizontes y se conjugó con las demás transformaciones urbanas y de las costumbres (Esquivel, Simonetta y Zapata 2008, 2009). La expresión más nítida fue que el coleccionismo de piezas artísticas e históricas encontró su razón de ser entre los sectores de altos recursos de la ciudad, una práctica que, por lo demás, ya contaba con antecedentes de vieja data entre sus pares porteños (Baldasarre 2006). Con todo, hay que tener en claro que esta práctica no solamente fue el producto de la mayor o menor capacidad pecuniaria de estos hombres sino también de un intento consciente de plasmar una lógica inmaterial pero igualmente diferenciadora, cuyo eje estaba puesto en el gusto y el refinamiento de los hábitos. En cierto sentido, el conjunto de objetos coleccionados coadyuvarían en la misión de construir un paradigma burgués de lo ostensible y de la imagen de quien los poseía (Zapata, Simonetta y Esquivel 2010).

En síntesis, fue en aquel contexto sociohistórico de la Rosario de principios del novecientos cuando se formaron algunas de las principales colecciones dedicadas específicamente a las artes plásticas y a objetos históricos en un sentido amplio (Simonetta y Zapata 2009, 2010). Una de las colecciones que sobresale, tanto por su derrotero de conformación como por el destino particular que tendrá con el tiempo, fue justamente aquella reunida por el matrimonio de Odilo Estévez Yánez y Firma Mayor. En el largo plazo, una parte importante de los bienes que conformaron esta particular colección serían destinados, por voluntad de sus dueños, a formar parte del patrimonio estables de algunos de los museos importantes de la ciudad, lo que a posteriori influirían en la demarcación de una imagen pública del matrimonio.

De este modo, y una vez clarificado el contexto que explica la existencia del coleccionismo como práctica de consumo cultural, se vuelve fundamental que a continuación reconstruyamos, por un lado, la vida de estas dos personas y la miríada de mecanismos del mercado del arte activados para poder acceder a diferentes objetos a los efectos de comprender las formas en que se llevó a cabo, en este caso particular, el consumo de piezas particularmente connotadas por su antigüedad, sus creadores o su lugar de procedencia; y por el otro, caracterizar las opciones estéticas y las improntas étnicoidentitarias que prevalecieron en tal práctica, así como los móviles particulares que guiaron la donación de parte del acervo.

\section{Detrás del bronce institucional: la vida de un matrimonio burgués y su colección}

Proveniente de una familia de cómoda posición económica originaria de Freas de Eiras, provincia de Orense, Galicia (España) ${ }^{1}$, Odilo Estévez Yánez emigró a la Argentina a

\footnotetext{
${ }^{1}$ El padre de Odilo, don Manuel Estévez Gil, se desempeñaba como
} 
la edad de 14 años. Luego de haber acumulado cierto capital, primero como empleado de comercio en el molino yerbatero Macías (en la ciudad de Colón, Entre Ríos) y posteriormente como corredor en el Molino Yerbatero de Núñez y Gibaja -donde se le había asignado el circuito que atravesaba las regiones del norte y noreste argentinos, incluyendo la ciudad de Posadas- (Sinópoli 1994: 24), Odilo se instaló definitivamente en Rosario donde, junto a sus socios Carlos y Arturo Escalada, fundó en 1905 la Yerbatera Paraguaya, epicentro de su actividad económica. Al año siguiente, ante la separación de los Escalada, se asoció a Ángel Muzzio y Humberto Guerzoni, con la consiguiente aparición de la firma Estévez \& Cía., quedando su hermano Emilio como apoderado de la misma, Odilo como "socio jefe" y los señores Muzzio y Guerzoni como "comanditarios" (Monos y Monadas 11-XXX, 1911: s/p.; Lloyd 1911: 619).

El negocio de la yerba mate fue una de las ramas industriales más relevantes de la ciudad Rosario puesto que mostró, al igual que la de la fabricación de harinas, el fuerte impacto que la transformación de las materias primas podía tener sobre el universo de los productores primarios y los secundarios, el imperioso desarrollo tecnológico y una compleja organización en secciones especializadas. A medida que la demanda de este producto -que formaba parte de la dieta alimentaria básica de los argentinos- se incrementaba, se produjeron rápidas modificaciones técnicas, espaciales y productivas, experimentando cambios en su estructura que hicieron que sobrepasara los niveles medios del conjunto manufacturero. No es casual entonces que Estévez participara de este proceso, inicialmente como empleado en tierras entrerrianas para luego convertirse en un poderoso empresario que tuvo el capital y el conocimiento suficientes para montar su propio proyecto en la ciudad, acceder a nuevas tecnologías -como los molinos, fuerza motriz suministrada por máquinas de vapor y motores eléctricos de origen inglés-, la anexión de otras empresas similares y la articulación de la producción con la importación. Es innegable que la inserción inicial de Estévez en la casa Macías le resultó fundamental para poder aprehender los resortes que se ponían en movimiento en el negocio yerbatero, conocimientos que luego trasladó a su propia empresa de Rosario.

La actividad yerbatera, conjugada posteriormente con la compra de tierras para la explotación agropecuaria (actividad que ocupó los últimos años de la vida de

juez o notario y era dueño de unas cuantas tierras de las que, aun desde estos lares, algunos de los hermanos de Odilo podían hacer usufructo. El matrimonio de Manuel Estévez Gil y Generosa Yánez Reza tuvo nueve hijos, de los cuales cuatro emigraron a la Argentina en distintos momentos. Posiblemente Odilo haya llegado al país a partir del llamado de alguno de sus hermanos o de paisanos, quienes tal vez lo hayan ayudado a ingresar en los molinos antes mencionados. Tal como relata una sobrina de Odilo, Nidia Estévez de Recalde Cuestas, la casa paterna en Freas de Eiras contaba con una importante biblioteca y, posiblemente, con un buen número de cuadros y obras de arte (Dell'Aquila 2007).
Estévez) le hicieron ganar un espacio notable en el mercado local y regional. En este sentido, las estrategias puestas en juego por este burgués ratifican -como ha mostrado Jorge Sábato (1988)- cómo la vieja dinámica de los sectores propietarios de inserción multisectorial y de diversificación hallaba en la actividad agropecuaria, manufacturera y financiera nuevos campos atractivos para una ganancia rápida. Esto significaba pasar de rama en rama sin atarse definitivamente a ninguna ni profundizar totalmente la inversión sino, por el contrario, combinando diversos tipos de emprendimientos en función de los nichos económicos no totalmente satisfechos y en relación a las posibilidades concretas de acumulación y de presión frente a las reglas que imponían el Estado y los sectores involucrados.

Odilo encontró su perfecta ubicación en el entramado social rosarino al contraer matrimonio con Firma Mayor en 1899, hija de Antonia Taltabull y del catalán Pedro Mayor, propietario de una de las fundiciones y herrerías más importantes de la ciudad entre 1880 y 1890 (Sinópoli 1994: 25). Como buen burgués, ingresó a la esfera pública de la ciudad a partir de diversos ámbitos de sociabilidad política, étnica y de clase. Desde la política, llegó a ser concejal por la Liga del Sur entre 1911 y 1912, dada su amistad con el demócrata-progresista Lisandro de la Torre (1868-1936). Fue socio fundador del Club Argentino de Pelota (desde el 18 de julio de 1922), socio durante cuarenta años del elitista Club Social (fundado en 1874); un asiduo concurrente del Club Español, espacio de sociabilidad burgués por excelencia de la colectividad española radicada en la ciudad (Águila y Caldo 2008), a lo que añadió más tarde su desempeño como miembro de la Comisión del Hospital Español entre 1930 y 1937.

Este gallego fue además un perspicaz actor en las gestiones culturales y políticas destinadas a las artes plásticas, por ejemplo, permitiendo la reproducción de obras de su colección en la revista El Círculo, de la asociación homónima (Armando 1998; Fernández 2010), y aportando publicidad de "Yerba 43", la Yerbatera paraguaya de Estévez, para el sustento material de dicha revista (El Círculo 1924-1925); asistiendo a eventos o convocatorias de tal grupo ${ }^{2}$ y ocupando los cargos de tesorero, vocal y vicepresidente en la Comisión Municipal de Bellas Artes, en 1929, 1930 y 1931 respectivamente, punto cúlmine de su presencia pública (Comisión Municipal de Bellas Artes 1929: 5; 1930: 8; 1931: 3). Por su parte, un artículo sin firma aparecido años después en el diario porteño La Prensa lo sindicaba ya no como un empresario yerbatero sino como un "conocedor" y "apreciador" de arte al presentarlo como "vicepresidente de la Comisión Municipal de Bellas Artes de Rosario,

\footnotetext{
2 Entre dichas actividades se cuentan distintas muestras, como la Exposición de Arte Retrospectivo de 1923, organizada por la asociación El Círculo en ocasión de la visita del entonces Presidente de la Nación Marcelo T. de Alvear y de su esposa, Regina Paccini, a la ciudad (El Círculo 1923), y los diferentes salones organizados a partir de ese momento (Simonetta, Zapata y Esquivel 2011);
} 
dedicado al estudio y colección de obras de arte" ( $L a$ Prensa 1931: s/p.) $)^{3}$.

La tarea de creación de una imagen pública por parte de Odilo fue emprendida siempre en conjunto con su esposa Firma, quien tuvo un rol central en los círculos culturales y artísticos, inclusive luego de la muerte de su esposo. Firma no se dedicaba demasiado a actividades benéficas como otras damas de la alta sociedad (Dalla Corte y Piacenza 2006; Bonaudo 2006), pero sí gustaba del restringido ámbito de la visita (García 2006: 101-103) y de algunas salidas con su marido a aquellos círculos y ámbitos de sociabilidad burguesa a los que pertenecían. En este cuadro, la faceta filantrópica del matrimonio se consumó a partir de donaciones precisas realizadas al Museo Municipal de Bellas Artes, que así se hizo acreedor en 1922 de una obra de Alfredo Guido (Cristo yaciente) y de cuatro obras más en 1929, las que habían obtenido la recompensa "Premio Estévez Adquisición" en ocasión del XI Salón de Rosario (Comisión Municipal de Bellas Artes 1929). No obstante, el gran beneficiado fue el Museo Histórico Provincial, institución creada en la ciudad el 8 de julio de $1939^{4}$, al cual Firma donó algunas piezas ${ }^{5}$ y cedió en préstamo otras tantas para la Exposición de Arte Religioso Retrospectivo que, en adhesión a los actos de Coronación de la Virgen del Rosario, se organizó en la sede del museo en 1941 (Montini 2008).

Desde que el museo consolidó su posición en el ámbito local y regional, Firma colaboró intensamente en lo que hacía a su organización y fomento. Así, formó parte en 1951 de la primera Comisión Directiva de la Asociación Amigos del Museo Histórico Provincial, fundada un año antes, junto a personalidades reputadas del ámbito local (como la señora Regina Paccini de Alvear, el cardenal y obispo de Rosario Caggiano y el político Manuel María de Iriondo). Su designación como vicepresidenta primero y socia honoraria después obedeció, como ha asegurado en su crónica Edgardo Oliveira Cézar, a "la simpatía y destacada colaboración prestadas a la Asociación y al Museo" (Oliveira César 1999: 26). Tal vez por eso mismo fue nombrada miembro del Instituto Bonaerense de Numismática y Antigüedades en 1953. Este hecho no es

\footnotetext{
3 Álbum de recortes. Repositorio Archivo Museo Municipal de Arte Decorativo "Firma y Odilo Estévez".

${ }^{4}$ La fundación del Museo Histórico Provincial (hoy Museo Histórico Provincial "Dr. Julio Marc") ha sido analizada en diferentes artículos (Zapata y Simonetta 2010; 2011b; 2011b; Zapata, Simonetta y Mansilla 2011).

${ }^{5}$ Entre las piezas donadas destacamos dos chapas, un atril para misal cuatro candeleros, todo de plata del siglo XVIII; un farol colonial y dos guías procesionales también de plata; un mate de Chacabuco que, en plata y oro, tenía los escudos argentino y chileno; las efigies de San Martín y O'Higgins, junto con escenas de campaña; una lámpara colgante de seis velas de plata colonial del siglo XVIII y un plato de porcelana Royal Derby con el monograma de Bernardino Rivadavia. A estos se agregaron, con posterioridad, un copón de cristal de la sucesión Victoria Aguirre; un jarrito de coco y un documento histórico de 1821 donde se consigna como Ministro de Relaciones Exteriores del Perú al Dr. Juan García del Río (Oliveira César 1999).
}

casual ya que, para la misma época, la Asociación Amigos del Museo Histórico Provincial había logrado obtener un vasto prestigio entre los círculos numismáticos de Buenos Aires a través de la reconocida figura del Dr. Julio Marc (1884-1965), uno de los principales impulsores -junto a Ángel Guido (1896-1960)- del Museo Histórico Provincial de Rosario y su posterior director.

Firma no sólo cedió su casa para las reuniones de la Asociación en varias oportunidades sino que, además, lo hizo para otras ocasiones importantes, por ejemplo para recibir y agasajar a los prelados extranjeros que participaron del V Congreso Eucarístico Nacional (1950). Sobresale el hecho de que, más tarde, Firma se vincularía uno de los acontecimientos que marcó fuertemente la historia de la ciudad de Rosario: la inauguración del Monumento Nacional a la Bandera en 1957 (Rovira et al. 1999; Hourcade 2001). Su hogar sería nuevamente el espacio elegido para que las damas de Rosario confeccionaran, con motivo de este hecho, la primera enseña patria que flamearía en el mastil, antiguo blasón que actualmente se muestra en la galería de honor de este monumento.

Odilo y Firma iniciaron la tarea de coleccionar piezas históricas y artísticas en la década de 1910, aunque el momento descollante de la misma se produciría en la década siguiente, apelando a múltiples modalidades de compra. En primer lugar, no dudaron en recurrir a reputadas casas de comercio de arte bonaerenses que en aquel momento nutrían las principales colecciones privadas de la burguesía porteña. Buenos Aires también sería el lugar elegido para hacerse de mobiliario y objetos decorativos en general. ${ }^{6}$ Tuvieron también su lugar las compras directas a otros coleccionistas o la utilización de los servicios de intermediarios ${ }^{7}$. Los negocios de arte en el Viejo Continente

\footnotetext{
6 En la sucursal de Nordiska Kompaniet adquirió, entre otros, Belisario (de Pascal) en 1924, Presentación de Laura y Petrarca al emperador Carlos IV en la corte del Papa de Avignon (de Vacslav Brozik), Niño del huaco (de Jorge Bermúdez) y algunos objetos de la Sucesión Victoria Aguirre, como columnas portuguesas, cristal de roca, carpetas y candelabros. Otras compras lo ligaron directamente a la casa Geriso (donde adquirió Pastoral, de François Boucher) y a la Galería Witcomb \& Cía (donde obtuvo, en 1922, Inundación en la Plaza San Marcos, de Félix de Ziem y Retrato de una dama con perrito, de Adolphe Monticelli, en 1924). En Thompson Muebles adquirió los mármoles titulados El baño forzado (de Urbano Luchéis), Primer beso (de Ferdinando Andreani) y, Pastorcita con huso (de Andrea Cambi), lo que fue completado con la compra de marfiles, sillas isabelinas laqueadas en negro y una alfombra Kouba. En el mercado rosarino, estos comercios de "objetos de arte y antigüedades, muebles de estilo y decoración" estaban presentes de la mano de Papis Hnos y de la Casa Castellani. En el mercado de arte rosarino sólo adquirió Cazadores árabes (de Eugéne Frometin, comprado en la sucursal local de Casa Witcomb) y Marité (de Herbert, vendido por Pedro F. Vicuña).

7 Tal es así que compró a Antonio Maura el Retrato de Mrs. Sarah Giddons (copia de la pintura de Thomas Lawrence), a Francisco Secco la Escena Cortesana de Salvatore Frangiamone (a lo que sumaron estatuas de bronce y marfil); la viuda de Ángel Macarrón le vendió en 1925 la obra de Eugenio Lucas Retrato de una dama y Franco Morales de Acevedo hizo lo propio en 1929 al desprenderse de un marfil anónimo titulado San José y el Niño. Sus intermediarios más solícitos
} 
también abastecieron a este matrimonio coleccionista ${ }^{8}$

El resultado de recurrir a esta multiplicidad de modalidades de compra fue la reunión de piezas de los más variados estilos, orígenes y temáticas, en la que no estuvieron ausentes los artículos orientales o los ceramios precolombinos, aunque siempre con la mirada puesta en Europa como fuente absoluta de obras de arte y como proveedora indiscutida también de expertos. No obstante, este variopinto paisaje no opacó la fuerte impronta de lo español en la elección de objetos artísticos. Sin lugar a dudas, en medio de esa primera impresión de eclecticismo podemos encontrar directrices más o menos expresas que guiaron su práctica coleccionista. Para Estévez existió un modelo latente -muchas veces poco formal y orgánico o, incluso, poco consciente-, que inclinó el gusto del comprador hacia determinado tipo de obras (Baldasarre 2006: 101). Esto implica una identificación de Estévez con su realidad de inmigrante español y el deseo de reproducir, a pequeña escala, una parte del terruño de origen (Dell'Aquila 2008).

En suma, la calidad de las adquisiciones que llevó a cabo el matrimonio y la biblioteca de Odilo, formada a través de los años e integrada por publicaciones de tipo enciclopedista, revistas y libros dedicados al arte -en su mayoría de principios del siglo $X X^{9}$-, nos permiten inferir que no se trata de un simple caso de coleccionismo amateur o improvisado, guiado torpemente por los avatares de las modas de la época. En todo caso, la serie de argumentos que hemos venido exponiendo prueba que Estévez y su mujer, sobre todo el primero, poseían cierto conocimiento del ámbito artístico, la producción, la lógica del mercado y de los agentes que actuaban en él, una suerte de experticia que les sirvió no sólo en la búsqueda de oportunidades sino también de buenos asesoramientos que colaboraran en las decisiones a tomar

fueron José María Pérez Valiente de Moctezuma -quien tuvo intervención en el asesoramiento para la compra de Jonás arrojado a la playa por la ballena, de Alessandro Magnasco, y de Retrato de Fernando VII, de Vicente López Portana, adquirida en Buenos Aires en 1926- y José Cavestany, a través del que se hizo acreedor de Corrida de toros, de Luis Alcázar (en 1924) y Retrato de un joven, atribuido a El Greco, obras que se encontraban en territorio español.

8 En 1928, la casa londinense Lewis Simmons le vendió Retrato de María Teresa de Apodaca (atribuida a Goya), Retrato de un gentilhombre (de Jacques Louis David) y Aves de corral (de Melchior de Hondecoeter). En París adquirió, en 1922, Retrato de un caballero español, y tres años después hizo lo mismo en la casa milanesa de E. M. Subert con la pintura El profeta Jonás arrojado de la ballena (atribuida a José de Ribera).

9 Entre las obras existentes en la biblioteca encontramos las colecciones Grandes pintores, Los grandes escultores des escultores y Les grandes artistes; una gigantesca publicación por tomos y por láminas titulada Arte y Decoración en España, cuyos tomos van de 1918 a 1930 y cuyo contenido expresa proyectos de casas en cuanto a diseño de mobiliario en distintas regiones y épocas de España. Luego, el Libro de Oro, correspondiente a la Exposición de Sevilla de 1928; y finalmente, revistas como La Esfera (números correspondientes al período 1917-1930) y algunas entregas de El Mundo Ilustrado y de La Ilustración Española y Americana. Repositorio del Archivo del Museo Municipal de Arte Decorativo "Firma y Odilo Estévez" respecto de adquirir una determinada obra de arte cuando emergían las dudas o la simple sospecha sobre el valor y la autenticidad de las piezas.

Ahora bien, esta gran colección merecía un espacio donde cobijarse y poder mostrarse en toda su plenitud. Esto explica la decisión de Estévez de adquirir en 1921 una propiedad que significó un gran aporte al capital material y simbólico del matrimonio por varias razones. El principal fundamento de esta elección debió obedecer, sin duda, a la posibilidad de levantar, sin ningún tipo de impedimento, un espacio exclusivo, propicio y privilegiado, lleno de obras de arte y objetos preciosos que reflejasen a la perfección las afecciones y pretensiones de sus propietarios. El sitio en el que se emplaza la misma agrega otro elemento de importancia: la antigua casa de Melitón Ibarlucea (1830-1901), un activo empresario y comerciante que se desempeñó como presidente del Banco Provincial de Santa Fe y como jefe político de la ciudad hacia fines del siglo XIX, fue un espacio residencial muy disputado por la burguesía de aquel entonces, dada su cercanía a la Catedral y al proyecto de erguir en sus cercanías a la Bolsa de Comercio de Rosario.

Odilo Estévez y Firma Mayor trataban pues de erigir una casa en la que no faltasen los detalles representativos de las preferencias de una clase social muy concreta, la burguesía local, de la cual se sentían que formaban parte sin tribulaciones de algún tipo. Las posteriores reformas arquitectónicas que se introdujeron no hicieron más que consolidar la imagen de una casa-burguesa propiamente dicha, es decir, la de una fastuosa mansión que reflejaba el importante nivel alcanzado en materia de negocios y posibilidades de acumulación. A la vez, los nuevos espacios profundizaban las características ibéricas (siendo reforzado el carácter identitario y la filiación étnica de sus nuevos dueños), a la vez que las combinaban con otras tendencias en boga en aquella época (Rigotti y Bragagnolo, 1981). De esta manera, la nueva casa y sus dependencias actuaban como escenarios en los que los objetos eran los protagonistas principales.

\section{La memoria pública de un patrimonio: la fundación del Museo}

A partir de la lectura del testamento de Firma Mayor de Estévez, el 10 de marzo de 1964 se iniciaba el acto de traspaso al dominio público de la casa y de una parte considerable de la colección que el matrimonio había reunido en más de 40 largos años de viajes, subastas y prosperidad. La última voluntad de Firma recién se formalizaría hacia 1968, conformándose un museo de características particulares basado en aquel patrimonio que confería a estos personajes-donantes una preeminencia insoslayable en el ámbito local y nacional, y que asimismo proyecta aún hoy una especificidad al acervo rosarino. El potencial rememorativo cargado sobre aquellas obras se materializaba en el futuro deparado a 
las piezas. Esta era la senda que siguió Firma a partir de la expresión de su voluntad de donar la casa y parte de la colección a la ciudad:

“...y sean mi mejor contribución para el acervo cultural y espiritual de mi ciudad, pues estimo que las obras de arte de todo género de que hago legado son de mérito y valores dignos de ser libremente conocidos y apreciados por todos y en todas las épocas, sirviendo también como base de estudios y enseñanzas" (Copia del Testamento de Firma Mayor de Estévez) ${ }^{10}$.

El acto de donación condujo a que todo objeto que se depositara en el museo fuera excluido de la apropiación privada, favoreciendo la aprehensión pura que había sido solapada en su oferta como artículo a la venta, participando activamente en aquellas luchas por el capital simbólico y por los procesos de legitimidad. Fueron estas piezas las que, excediendo el dominio de la esfera privada pero vinculándose y sosteniéndose a partir de ésta, conformaron el patrimonio fundacional de uno de los principales museos de la ciudad.

Si bien el testamento de Firma se leyó dos días después de su fallecimiento (ocurrido en 1964), las gestiones para la formación y habilitación del museo se demorarían hasta 1968. El legado había sido aceptado por el Decreto $N^{\circ} 4824$ del Concejo Deliberante, con fecha del 7 de diciembre de 1964. La Municipalidad tomó posesión del mismo mediante el Decreto $N^{\circ} 33542$ del 13 de diciembre de 1966, el día 16 del mismo mes. No obstante, cuando el museo abrió sus puertas al público, la colección y la organización de los espacios de la casa habían atravesado un importante proceso de reorganización, que fue marcando cambios en la imagen que se proyectaría de la pareja (La Capital 1968). ${ }^{11}$

En el caso del Museo Municipal de Arte Decorativo "Firma y Odilo Estévez", siguiendo una política tendiente a la organización museográfica del espacio del museo, su primer director, Pedro Sinópoli12, dio nueva forma a las diversas salas. Las condiciones en que se encontraba la casa (y la colección) hacia 1968, fueron descriptas por Sinópoli, marcadas por el abigarramiento de los espacios interiores de la casa:

“En la mañana de mi llegada, el espectáculo que se me presentó era el de un conjunto de ambientes saturados de muebles y objetos dispuestos con un orden disparatado, o mejor dicho, una multitud de cosas polifórmicas, de diferentes estilos y

\footnotetext{
10 Repositorio del Archivo del Museo Municipal de Arte Decorativo "Firma y Odilo Estévez".

11 Álbum de recortes. Repositorio del Archivo Museo Municipal de Arte Decorativo Firma y Odilo Estévez.

12 Pedro Sinópoli fue director Museo Estévez en dos oportunidades: 1968-1976 y 1985-2006.
}

épocas, que chocaban física y visualmente entre sí, creando una especie de atmósfera opresiva. La semipenumbra de los espacios contribuía a la confusión general, pero apenas uno deslizaba la vista de un mueble a un objeto, de una talla a una pintura, advertía que en ese montón convivían conflictivamente piezas extraordinarias, la mayoría bellísimas, con otras menos bellas y otras, por suerte las menos, sin un valor museable o decididamente estrafalarias. Supuse que esa disposición acumulativa respondía a un criterio y a un supuesto orden muy personal de los Estévez, al que se sumaba un cierto 'horror vacuii' característico de la "decoración de interiores" de principios del siglo. Tanto es así que muebles franceses, ingleses y renacentistas, platería colonial, marfiles europeos y orientales, arcas españolas, porcelanas europeas y cerámicas precolombinas, por mencionar algunos ítems del conjunto, se mezclaban en las 'salas francesas', en el salón de fumar, en el comedor -con un insólito aire angloitaliano- y principalmente en el hall central -que anteriormente había sido el patio principal de la casa- y que luego los Estévez convirtieron en un gran ámbito con una decoración resueltamente española o mejor aun de inspiración neocolonial. Alli es donde más resaltaba esa especie de revoltijo estilístico pues recuerdo, por ejemplo, que sobre la chimenea de nogal tallado se alineaban unos jarros alemanes de marfil y piezas orientales del mismo material. Por otra parte, qué decir de las pinturas, que tampoco guardaban alguna relación entre sí en cuanto a cómo y dónde estaban colgadas. Cabía preguntarse qué sentido tenía para ellos una rigurosidad estilística y cabía pensar que ubicaron sus cosas en la forma que a ellos les complacía disfrutarlas" (Sinópoli 2007: 1).

Para ser visitado por el público, las piezas fueron reordenadas por períodos, evitando el eclecticismo imperante, dándole cierto sentido para hacer más viable su exhibición. En efecto, al depositar estos bienes privados en el dominio público dichos objetos pasaron a observar determinados parámetros inscriptos en prácticas de exhibición y conservación museológica y museográfica. Ya no dependían de los criterios que pudieron haber guiado a sus antiguos poseedores. Ahora la responsabilidad de dotarlos de nuevos usos y significados recaía en las autoridades del museo establecido por el Estado municipal. Esto significó, por un lado, una tarea de "discriminación" de las piezas en función de la cual el director del nuevo museo se encargó de decidir qué objetos se mostrarían y cuáles "era necesario guardar en virtud de jerarquizarlas." (Sinópoli 2007: 4).

Por otro lado, buena parte de la colección fue reubicada, agrupando objetos afines para crear una compaginación museológica sobre la cual edificar el diseño de las 
diferentes salas. A partir del Hall Central se abren los principales ambientes de la casa, en el cual se pueden apreciar varias piezas de la colección. Retomando nuevamente el relato de Sinópoli, el mismo anota que:

"Se puede mencionar sintéticamente cuáles son las salas que se crearon entonces y que nada tienen que ver con lo que eran antes de la conformación del Museo. Son las dos salas que llamamos "españolas", sistematizadas en los ambientes que fueron el escritorio y el salón de fumar de la casa. Allí reuní magníficas obras españolas de los siglos XV al XIX. El Hall Central, que está totalmente ordenado en oposición al criterio de los antiguos dueños que los habían abarrotado de muebles, objetos y cuadros de valor y estilos dispares, sin posibilidades de ser apreciados y de percibirse la clara especialidad del ambiente. La creación de la llamada "Sala de Platería" en el vestidor del Sr. Estévez (más tarde trasladada a otro ambiente) y el dormitorio principal -que se recibió sin muebles-y que se dedicó a exhibir una especie de miscelánea surgida del carácter multifacético de la colección. Las otras salas, que llamé "Francesas" y el comedor, traté de ordenarlas respetando el aspecto que tenían anteriormente, habida cuenta que aquello que es musealizado debe ser considerado a la par que los testimonios de la vida que se ha deslizado en los ambientes habitados: los adornos, los objetos de uso cotidiano aquellos para las ocasiones de representación que responden a los valores tales como la clase social de pertenencia, el gusto y la riqueza de los dueños de la casa." (Sinópoli 2007: 6)

Como puede verse, aquí está actuando una conceptualización muy fuerte de lo que debe ser un museo, en tanto espacio ordenado a los fines de mostrar al público los objetos más relevantes o dignos de ser expuestos, fundamentando sus contenidos en la idea de que el museo pueda transmitir conocimientos y comunicar merced a su capacidad técnica, su personal especializado y su programa museológico. Este ideal museológico y la necesidad de resguardar y restaurar parte de la colección y del edificio mismo impulsaron al cierre del museo por trece meses entre 1993 y 1995. Su puesta en valor incluyó un trabajo bastante minucioso en los cielorrasos, estucos, pisos, textiles, cambio de los revestimientos de damasco, renovación de cortinados, iluminación, creación de nuevas salas, restauración integral de la fachada de calle San Lorenzo, restauro de cuadros, marcos y otros objetos de arte y creación del espacio para colocar una pequeña cafetería.

En este sentido, la selección de lo "mostrable" fue creando y reflejando en el discurso museológico una imagen particular de los habitantes de la casa. De acuerdo con esta necesidad, el museo fomenta una experiencia personal y exploratoria en el público visitante, pero que sin lugar a dudas no carece de prescripciones vinculadas a lo que se pretende que se escuche y vea. En este acto, se diseñaba, proyectaba y materializaba una nueva exposición como una acción profesional, racional y conciente respaldada por un cuerpo coherente de conocimientos museográficos que tenía en cuenta la preservación íntegra del patrimonio, el público, la expresión de una idea, el funcionamiento del museo como una institución inserta en una sociedad determinada y una cultura específica, con reglas y sistemas acordados de convivencia colectiva. El museo Estévez fue concebido como un espacio donde se podían observar los muebles y las reliquias que el matrimonio antes guardaba celosamente en el seno de lo íntimo y lo privado (Museo Municipal de Arte Decorativo "Firma y Odilo Estévez" Cátalogo s/f.). La memoria familiar es producida por objetos familiares reapropiados bajo otra lógica y exhibidos públicamente. Éste es precisamente el proceso que posibilitó la formación del Museo Municipal de Arte Decorativo Firma y Odilo Estévez: una patrimonialización bajo auspicio municipal de la memoria familiar ( $L a$ Capital 13-VII-2008). A su vez, este movimiento puede observarse en el sentido contrario, como la filiación de la sociedad rosarina con la herencia de un matrimonio burgués (Museo Municipal de Arte Decorativo "Firma y Odilo Estévez" Guión Museográfico para las Visitas 2008)

También sería justo incorporar al análisis de este museo la presencia de los inmigrantes en Rosario y sus demandas por la búsqueda de narrativas identitarias que los representaran. Tal vez pueda pensarse que los objetos allí exhibidos vienen a satisfacer la necesidad simbólica de las colectividades de extranjeros (asentadas desde larga data en la ciudad) de presenciar en un marco iconográfico su aporte a la historia local. Así, dentro de la numerosa colección que integra el legado Estévez, un porcentaje elevado lo constituyen objetos procedentes de artistas españoles, italianos y franceses. Es decir, la apropiación del Museo Estévez puede ser entendida en una doble dirección: como un intento de una familia burguesa por imponer su memoria, pero también como un afán por transmitir, a través de las narrativas cristalizadas en la cultura material, los aires cosmopolitas no sólo de Firma y Odilo (ejemplo de que el sueño de fare l'America era posible y que había triunfado a través de ellos) sino de toda una sociedad.

En este sentido, el Museo Estévez debe intervenir como una instancia nostálgica, capaz de actuar como un espejo del pasado y del presente de la urbe. Su ideal promueve, frente a los intentos por quebrar los antiguos lazos con las patrias allende el océano, la historia de los grupos de inmigrantes que propugnaron fuertes cambios en la vida cotidiana de una ciudad sin pasado colonial, alcanzando posiciones sociales que en otros lugares hubieran estado veladas por la existencia de una clase patricia que detentaba las redes del poder. La estrategia del museo es, entonces, atender a un público 
que, identificado como argentino, no deja de reconocer simultáneamente la huella de la inmigración, donde es posible advertir los signos del genuino proceso que dio nuevos bríos a la ciudad de Rosario. Los referentes de esta configuración identitaria se definen desde el museo y buscan ser ratificados en la memoria inalterable de una dimensión pretérita y de un futuro anunciado.

Cuando el Museo Municipal de Arte Decorativo "Firma y Odilo Estévez" fue definitivamente inaugurado, la centralidad mayor la poseían las colecciones, es decir, la cultura material tangible organizada desde una narrativa particular cuya meta principal es reflejar un fragmento homogéneo y acotado de la identidad rosarina: el de la burguesía. En efecto, las prácticas museológicas puestas en juego en la primera etapa de gestión de la casa como una institución pública terminaron mostrando la construcción misma de una subjetividad enteramente clasista: una ciudadanía cultural que se identificará con la cultura material exhibida, y ésta última a su vez, dará testimonio del selecto grupo de adalides que promovieron el desarrollo de la historia, el arte y la cultura.

No obstante, ese sujeto colectivo nunca puede hablar por sí mismo. Debe ser representado en las colecciones de cultura material -reliquias, pinturas, objetos históricosmanipuladas por los administradores de las memorias públicas. Ya no es suficiente presentar al legado EstévezMayor para ser admirado sin ningún tipo de mediación. La conversión de la casa burguesa en casa museo obligó a emprender desde el ámbito político municipal una serie de tácticas que, amparadas tanto en las tendencias museológicas como en las técnicas museográficas, promovieran y facilitaran la apropiación de este legado privado como patrimonio cultural público de todo Rosario.

\section{Conclusiones}

A lo largo de este artículo, hemos procurado mostrar la intrincada conexión que existió -y que aún hoy persiste (Zapata y Simonetta 2011)- entre el acervo patrimonial que alberga una de las instituciones museológicas más importantes de la ciudad de Rosario y una particular representación social de la localidad y su realidad histórica. Es por ello que esta investigación sobre la historia social del significado de una colección privada de objetos de arte e historia, su derrotero y posterior posición en una entidad pública de carácter municipal como Museo Municipal de Arte Decorativo “Firma y Odilo Estévez" nos permite, como estudio de caso, poner de relieve los discursos desplegados sobre la donación de una colección originalmente privada a partir de la que se pretendía dotar a la ciudad de un repertorio visual del gran arte logrado por una de las familias más conspicuas de Rosario. En tal sentido, esa ofrenda inaugural fue muy significativa para el proyecto original del Museo, en tanto aseguraba una función pedagógica precisa a la institución. Tal función dialoga con la idea de una sociedad que albergó a ciertos actores, cuyas acciones (en pos de mostrar aires de civilidad en sus prácticas) y legados (en materia comercial e industrial a través del emprendimiento de la Yerbatera; en lo cultural y artístico, desempeñando funciones vinculadas a asociaciones de esta índole) fueron tributarios de la prosperidad económica y social que les brindó este espacio urbano.

Por otro lado, hemos visto cómo la orientación cultural de la colección sugiere integraciones selectivas tanto de la experiencia artística europea como de la americana, sobresaliendo la primera por sobre la segunda. En el contexto del museo, la importancia de un objeto pareciera que no está dada tanto por sus valores estilísticos, artísticos o tecnológicos sino por su capacidad para transmitir un mensaje. No obstante, el museo se ve atropellado en esta tarea por la reducción del objeto-documento al objetomemoria. La identidad de los Estévez en tanto burgueses y coleccionistas es recreada en los discursos del museo que dan cuenta de la pasión y del amor supuestamente desinteresado que unía al dueño con las obras de arte en su posesión y el fiel deber patriótico cumplido en otorgar a la sociedad bienes sumamente caros y emblemáticos de un sistema artístico al cual no todos podían acceder. Aquí también se representa y se resguarda la memoria de una fase pujante no sólo de pocos hombres sino de una comunidad.

Todos estos elementos se conjugaron de un modo particular para dar forma a la actual casa-museo que se muestra en Rosario, entendiéndola como una institución de preservación y muestra de objetos pero también como un espacio de irradiación de un mensaje y una memoria familiar, grupal y de la ciudad que la cobija y que se proyecta hacia la comunidad, poniendo en juego la necesaria relación entre el patrimonio y la sociedad que lo sustenta. La historia de vida rescatada, las modificaciones del edificio y los múltiples usos dados a la propiedad evidencian que este locus ha sido puesto en valor no sólo como el referente de un sector de la sociedad sino de una época determinada de nuestra localidad que a los ojos de la comunidad merece ser preservada. La casa-museo se vive como una muestra de algunas de las transformaciones sociales que se operaron desde fines del siglo XIX y se consolidaron en las primeras décadas del $X X$. Su historia, con la incorporación de los actores que han vivido allí, se convierte en un patrimonio intangible de Rosario, una suerte de ejemplo que enriquece el pasado de la misma.

Rosario, 20 de abril de 2011

\section{Agradecimientos}

Deseamos expresar nuestro agradecimiento a la Licenciada Analía Vanesa Dell'Aquila por su asesoramiento inicial, por su ayuda desinteresada y por haber compartido generosamente con nosotros buena parte de su material de investigación. En el transcurso del artículo se halla debidamente indicada su contribución. Este trabajo 
retoma, auque con modificaciones y ampliaciones, las principales cuestiones tratadas en dos ponencias presentadas en diferentes momentos: una, discutida en el marco del $3^{\circ}$ Encuentro "La Problemática del Viaje y los Viajeros". América Latina y sus miradas. Imágenes, representaciones e identidades (llevadas a cabo en la ciudad de Tandil en agosto de 2008) y otra, expuesta en las $1^{\circ}$ Jornadas de Educación e Investigación en los Museos (organizadas en Santa Fe, en septiembre del mismo año).

\section{Bibliografía}

Águila, V., P. Caldo. 2008. Pocos pero los mejores... Notas acerca de las prácticas asociativas del Club Español de Rosario, fines del siglo XIX y primeras décadas del siglo XX. Fernández, S., O. Videla (comps.), Ciudad oblicua. Aproximaciones a temas e interpretes de la Entreguerra Rosarina. pp. 153-175, La Quinta Pata \& Camino Ediciones, Rosario.

Armando, A. 1998. Entre los Andes y el Paraná: La Revista de "El Círculo" de Rosario. Cuadernos del Centro Interdisciplinario de Estudios de América Latina, Año IV, No 5: pp. 79-88.

Artundo, P. M. (org.) 2006. El Arte Español en la Argentina, 1890-1960, Fundación Espigas, Buenos Aires.

Baldasarre, M. I. 2006. Los dueños del arte. Coleccionismo y consumo cultural en Buenos Aires. Edhasa, Buenos Aires.

Benjamín, W. 1987 [1937]. Discursos interrumpidos I. Taurus, Madrid.

Bonaudo, M S. 2006a. La tierra y el sueño de fare l'America. Bonaudo, M. S. (comp.), La organización productiva y política del territorio provincial (1853-1912). Tomo VI de la Colección Nueva Historia de Santa Fe, pp. 31-55, Editorial Prohistoria / La Capital, Rosario.

Bonaudo, M S. 2006b. La complejidad del mundo de los negocios. Bonaudo, M. S. (comp.), La organización productiva y política del territorio provincial (1853-1912). Tomo VI de la Colección Nueva Historia de Santa Fe, pp. 57-83, Editorial Prohistoria / La Capital, Rosario.

Bonaudo, M S. 2006c. Cuando las tuteladas tutelan y participan. La sociedad Damas de Caridad. (1869-1894). Signos Históricos, Nº 15: pp. 70-97.

Dalla Corte, G.; P. Piacenza. 2006. A las puertas del Hogar. Madres, niños y Damas de Caridad en el Hogar del Huérfano de Rosario (1870-1920). Prohistoria Ediciones, Rosario.

Dell'Aquila, A. V. 2007. El gusto artístico de la burguesía rosarina en la conformación de un imaginario social. El caso de la colección de arte y objetos artísticos de Firma y
Odilo Estévez, 1910-1930. Informe de Beca. Secretaría de Cultura de la Provincia de Santa Fe, Rosario.

Dell'Aquila, A. V. 2008. La hispanidad en el gusto artístico de la burguesía rosarina. El caso de la colección Estévez, 1920-1930. Artundo P.; C. Frid (comps.), El Coleccionismo de Arte en Rosario. Colecciones, mercado y exhibiciones, 1900-1970, pp. 159-200, Fundación Espigas / Centro de Estudios Históricos e Información Parque España, Rosario.

Esquivel, M., L. C Simonetta, H. M. H. Zapata. 2008a. Las burguesías y el coleccionismo en la Rosario de entreguerras. A modo de balance y hacia una agenda renovada. Fernández, S.; O. Videla (comps.), Ciudad oblicua. Aproximaciones a temas e interpretes de la Entreguerra Rosarina, pp. 57-61, La Quinta Pata \& Camino Ediciones, Rosario.

Esquivel, M., L. C Simonetta, H. M. H. Zapata. 2008b. De casa burguesa a casa-museo. La construcción de la memoria pública de una familia rosarina: el caso del Museo Municipal de Arte Decorativo 'Firma y Odilo Estévez' de Rosario. Actas del $3^{\circ}$ Encuentro "La Problemática del Viaje y los Viajeros". América Latina y sus miradas. Imágenes, representaciones e identidades (Tandil, 14, 15 y 16 de agosto de 2008) [CDROM], CESAL-ISHIR/CONICET y Escuela de Historia - UNR, Tandil.

Esquivel, M., L. C Simonetta, H. M. H. Zapata. 2008c El porvenir de una colección. Imaginarios y representaciones de una familia burguesa: el caso del Museo Municipal de Arte Decorativo 'Firma y Odilo Estévez' de Rosario. Actas de las Jornadas de Educación e Investigación en los Museos. El museo como centro educativo, turístico y de investigación (Santa Fe, 12, 13 y 14 de septiembre de 2008) [CD-ROM]. Museo Etnográfico y Colonial "Juan de Garay" y Dirección Provincial de Patrimonio y Museos, Ministerio de Innovación y Cultura de la Provincia de Santa Fe, Santa Fe.

Esquivel, M., L. C Simonetta, H. M. H. Zapata. 2009. "Las memorias privadas de la distinción pública. Burguesía, coleccionismo, exhibiciones y museos en Rosario, primera mitad del siglo XX". Seminario Regional, Facultad de Humanidades y Artes, Universidad Nacional de Rosario, Rosario, 186 pp. Biblioteca de la Escuela de Historia.

Fernández, S. R. 1999. Burgueses, familia y empresa. Rosario en el cambio de siglo (1880-1910). Revista Travesías de Estudios Regionales, No 2: pp. 27-50.

Fernández, S. R. 2003. La negación del ocio. El "negocio" cultural en la ciudad de Rosario a través de la asociación "El Círculo" (1912-1920). Andes. Revista de Historia y Antropología, No 14: pp. 247-274.

Fernández, S. R. 2007. Poder local y virtud. Legitimación burguesa en el espacio local. Rosario -Argentina- en las primeras décadas del siglo XX. García Jordán, P. (ed.), Estado, región y poder local en América Latina, siglos XIX y XX. 
Algunas miradas sobre el Estado, el poder y la participación política, pp. 229-250, Publicacions i edicions de la Universitat de Barcelona, Barcelona.

Fernández, S. R. 2009. La revista El Círculo o el arte de papel. Una experiencia editorial en la Argentina del Centenario. EDITUM/Servicio de Publicaciones de la Universidad de Murcia, Murcia.

Fernández, S. R.; A. Pons; O. Videla. 1999-2000. Una burguesía local dentro de un espacio regional, Rosario, 1880-1912. Un intento de caracterización. Bonaudo, M. D. Campi, Daniel (coords.), Elites, cuestión regional y Estado Nacional. Argentina y América Latina, primeras décadas del XX. Volumen I. pp. 233-249, Instituto de Estudios SocioEconómicos, Universidad Nacional de Tucumán, San Miguel del Tucumán.

Frid de Silverstein, C. 1993. Parenti, negozianti e dirigente: la prima dirigenza italiana di Rosario (1860-1890). Rosoli, G. (ed.), Identità degli italiani in Argentina. Reti sociali, famiglia, lavoro, pp. 137-141, Centro Studi Emigrazione, Edizioni Studium, Roma.

Frid de Silverstein, C. 1994. Más allá del crisol: matrimonios, estrategias familiares y redes sociales en dos generaciones de italianos y españoles (Rosario, 1895-1925) Estudios Migratorios Latinoamericanos, № 28: 481-520.

Frid, C. L. 2006. Encontrando la clientela: comerciantes e inmigrantes en el sur de Santa Fe a fines del siglo XIX. Bernasconi, A.; C. Frid (eds.), De Europa a las Américas. Dirigentes y liderazgos (1880-1960), pp. 149-174, Editorial Biblos, Buenos Aires.

Frid, C. L. 2007. Del Puerto al Almacén Rural: circuitos comerciales y producción lanar en Santa Fe (1860-1890). Revista de Instituciones, Ideas y Mercados, $N^{\circ}$ 46: pp. 93-117.

Frid, C. L. 2008. Un programa de investigación sobre el coleccionismo de arte en Rosario. Artundo, P.; C. Frid (eds.), El Coleccionismo de Arte en Rosario. Colecciones, mercados y exhibiciones, 1880-1970, pp. 11-15, Fundación Espigas / Centro de Estudios Históricos e Información Parque España, Buenos Aires.

Gallo, E. 2004 [1983]. La pampa gringa. La colonización agrícola en Santa Fe (1870-1895), Edhasa, Buenos Aires.

García, A. 2006a. Una comunidad de lectores urbanizados. La visita, espacio de sociabilidad burguesa en la ciudad de Rosario, principios del siglo XX. Bonaudo, M. S. (dir.), Los actores entre las palabras y las cosas. Imaginarios y prácticas de un orden burgués. Rosario 1850-1930, pp. 147-171, Prohistoria Ediciones, Rosario.

García, A. 2006b. Lo público y lo íntimo. Fernández, S. R. (comp.), Sociabilidad, corporaciones, instituciones, Tomo VII de la Colección Nueva Historia de Santa Fe, pp. 121-138, Editorial Prohistoria / La Capital, Rosario.

Hourcade, E. 2001. Rosario, cuna de la bandera. Pagano, N.; M. Rodríguez (comps.), La historiografía rioplatense en la posguerra, pp. 139-155, La Colmena, Buenos Aires.

Lanciotti, N. De rentistas a empresarios. Inversión inmobiliaria y urbanización en la pampa argentina Rosario, 1880/1914. Santa Fe: Ediciones de la Universidad Nacional del Litoral, 2009.

Losada, L. 2008. La alta sociedad en la Buenos Aires de la Belle Époque. Sociabilidad, estilos de vida e identidades, Siglo XXI Editora Iberoamericana, Buenos Aires.

Losada, L. 2009. Historia de las elites en la Argentina. Desde la Conquista hasta el surgimiento del Peronismo, Sudamericana, Buenos Aires.

Megías, A. 1996. La formación de una elite de notablesdirigentes, Rosario, 1860-1890, Editorial Biblos, Buenos Aires.

Montini, P. 2008. El gusto por lo religioso: La Exposición de Arte Religioso Retrospectivo en el Museo Histórico Provincial de Rosario, 1941. Artundo, P.; C. Frid (eds.), El Coleccionismo de Arte en Rosario. Colecciones, mercados y exhibiciones, 1880-1970, pp. 201-237, Fundación Espigas / Centro de Estudios Históricos e Información Parque España, Buenos Aires.

Oliveira Cézar, E. 1999. Julio Marc y sus amigos del Museo, Talleres Gráficos de Ami Impresos, Rosario.

Pons, A.; R. Ruiz. 2006. Tras el velo del comercio, la materia prima se transforma. Una aproximación al perfil industrialmanufacturero de Rosario (1873-1914). Bonaudo, M. S. (dir.), Los actores entre las palabras y las cosas. Imaginarios y prácticas de un orden burgués. Rosario 1850-1930, pp. 15-45, Prohistoria Ediciones, Rosario.

Pons, A.; O. Videla. 2005. Formación de una burguesía local e inmigración española en la Rosario agroexportadora. Historia Regional, N²3: pp. 75-90.

Rigotti, A. M.; E. Bragagnolo. 1981. El edificio del Museo Estévez. Cuadernos de la Dirección General de Cultura - Serie Revista, pp. 109-119, Municipalidad de Rosario, Rosario.

Rovira, L.; D. P. Roldán; I. M. Martínez. 1999. La Patria a su Bandera. Discusiones en torno a la erección de un Monumento a la Bandera en la ciudad de Rosario. Prohistoria, № 3: pp. 299-310.

Simonetta, L. C., H. M. H. Zapata; M. Esquivel. 2008. Una mirada a los vínculos, prácticas y representaciones culturales 
en la Rosario de entreguerras: Burguesía, coleccionismo y espacio público. Fernández, S.; O. Videla (comps), Ciudad oblicua. Aproximaciones a temas e interpretes de la Entreguerra Rosarina, pp. 63-79, La Quinta Pata \& Camino Ediciones, Rosario.

Simonetta, L. C., H. M. H. Zapata; M. Esquivel. 2011. En busca del arte. La cultura asociativa burguesa y las prácticas sociales de la exhibición en Rosario, 1912-1940. Cambios y Continuidades, Año X, No 7: pp. 11-46.

Simonetta, L. C., H. M. H. Zapata. 2009. Las caras del burgués. Un ejercicio de reflexión acerca del coleccionismo, arte y cultura asociativa en Rosario, 1907-1930. Actas de las II Jornadas Nacionales de Historia Social (La Falda, 13 al 15 de mayo de 2009) [CD-ROM], Centro de Estudios Históricos "Prof. Carlos S. A. Segreti"/CONICET y Centro de Estudios de Historia Americana Colonial/Universidad Nacional de La Plata, Córdoba.

Simonetta, L. C., H. M. H. Zapata. 2010. Alta cultura, distinción pública y memorias burguesas en el prisma de la modernidad. Repensando la relación entre coleccionismo y museos en un espacio local. Rosario, primera mitad del siglo XX. Recordando a Walter Benjamin "Justicia, Historia y Verdad. Escrituras de la Memoria" Actas del III Seminario Internacional Políticas de la Memoria (Buenos Aires, 28, 29 y 30 de octubre de 2010) [CD-ROM], Centro Cultural de la Memoria Haroldo Conti, Buenos Aires.

Sinópoli, P. 1971.Una memoria sobre la musealización del patrimonio Estévez. Textos escritos en los años de gestión 1968-1976 y 1984-2006, s/p. Repositorio del Museo Municipal de Arte Decorativo "Firma y Odilo Estévez".

Sinópoli, P. 1994. El museo Estévez. Revista de la Bolsa de Comercio de Rosario, Vol. XL, No 1462: pp. 20-28.

Slullitel, I. Crónicas, documentos y otros papeles, Molachino Establecimiento Gráfico, Rosario.

Sonzogni, É. et al. 1987. Notas acerca de la problemática en la coyuntura de la primera posguerra" En: Anuario de la Escuela de Historia (UNR), No 12.

Tarragó, G. 2006. De la autonomía a la integración. Santa Fe entre 1820 y 1853, Tomo V de la Colección Nueva Historia de Santa Fe, Editorial Prohistoria / La Capital, Rosario.

Videla, O.; S. Fernández. 2000. La evolución económica rosarina durante el desarrollo agroexportador. Falcón, R.; M. Stanley (eds.), Historia de Rosario, Tomo I, pp. 55-100, Homo Sapiens, Rosario.

Zapata, H. M. H.; L. C. Simonetta. 2010. Un "templo de la historia" para la ciudad "sin pasado". Las memorias de la Nación y las tradiciones hispano-colonial y criolla en los primeros derroteros del Museo Histórico Provincial 'Dr. Julio
Marc' (Rosario, 1912-1950). Actas del XXX Encuentro de Geohistoria Regional (Resistencia, del 19 al 21 de agosto de 2010) [CD-ROM], Instituto de Investigaciones Geohistóricas - CONICET / Universidad Nacional del Nordeste, Resistencia.

Zapata, H. M. H.; L. C. Simonetta. 2011a. Dos formas de recordar, una forma de valorar. Las experiencias del Museo Histórico Provincial "Dr. Julio Marc" y del Museo Municipal de Arte Decorativo "Firma y Odilo Estévez" de la ciudad de Rosario (Argentina). Bresciano, J. A. (comp.), Las dimensiones de la memoria histórica en un mundo globalizado. Una aproximación interdisciplinaria, en prensa, Tradinco Editorial, Montevideo, 2011.

Zapata, H. M. H.; L. C. Simonetta. 2011b. Las configuraciones de sentido en el Museo Histórico Provincial de Rosario a principios del siglo XX: memorias visibilizadas, actores negados y pasados en pugna. Temas de Historia Argentina y Americana, № 18: 213-251.

Zapata, H. M. H.; L. C. Simonetta; M. Esquivel. 2010. De las fruiciones privadas a las políticas públicas: colecciones, exhibiciones y museos en la configuración de la burguesía. Rosario, primera mitad del siglo XX. Recapitulando una experiencia investigativa. Achilli, E; G. Bernardi et al. (coords.), Vivir en la ciudad: tendencias estructurales y procesos emergentes, pp. 447-461, Centro de Estudios Antropológicos en Contextos Urbanos, Facultad de Humanidades y Artes, Universidad Nacional de Rosario / Laborde Editor, Rosario.

Zapata, H. M. H.; L. C. Simonetta; M. L. Mansilla. 2011. La fundación del Museo Histórico Provincial "Dr. Julio Marc": patrimonio, identidades y representaciones del pasado (Rosario, 1912-1950)". Anuario de Arqueología (Universidad Nacional de Rosario), Vol. 4 (1): 121-135.

\section{Fuentes, Archivos y Fondos Documentales Consultados}

\section{A. Periódicos y Revistas}

La Capital (Rosario), Archivo del Diario La Capital (Rosario) La Tribuna (Rosario), Biblioteca y Escuela de la Asociación de Mujeres de Rosario (Rosario)

La Prensa (Buenos Aires), Biblioteca y Escuela de la Asociación de Mujeres de Rosario (Rosario)

Monos y Monadas (Rosario), Archivo del Museo Histórico Provincial "Dr. Julio Marc" (Rosario)

Revista de la Bolsa de Comercio de Rosario (Rosario), Hemeroteca de la Biblioteca Argentina "Juan Álvarez" (Rosario)

Revista El Círculo Órgano de la institución cultural El Circulo (Rosario), Archivo de El Círculo (Rosario)

\section{B. Catálogos, Actas y Guías de Exposiciones}

Comisión Municipal de Bellas Artes, XI Salón de Rosario, Rosario, agosto de 1929. Biblioteca Argentina "Juan Álvarez" (Rosario)

Comisión Municipal de Bellas Artes, XII Salón de Rosario, 
Rosario, septiembre de 1930. Biblioteca Argentina "Juan Álvarez" (Rosario)

Comisión Municipal de Bellas Artes, XIII Salón de Rosario, Rosario, julio de 1931. Biblioteca Argentina "Juan Álvarez" (Rosario)

Museo Histórico Provincial, Exposición de Arte Religioso Retrospectivo. Coronación de la Virgen del Rosario (4 al 19 de octubre de 1941), Rosario, 1941. Archivo del Museo Histórico Provincial "Dr. Julio Marc" (Rosario)

Museo Municipal de Arte Decorativo "Firma y Odilo Estévez", Catálogo, Fundación Banco Municipal de Rosario, Rosario, s/f. de edición. Archivo del Museo Municipal de Arte Decorativo "Firma y Odilo Estévez" (Rosario)

Museo Municipal de Arte Decorativo "Firma y Odilo Estévez",
Guión Museográfico para las Visitas, Municipalidad de Rosario, Rosario, 2008. Archivo del Museo Municipal de Arte Decorativo "Firma y Odilo Estévez" (Rosario)

\section{Publicaciones}

Amuchástegui, N. Álbum. Al Museo Municipal de Bellas Artes Juan B. Castagnino, Rosario. Su origen, Compilación donada por el autor, s/f. Repositorio documental del Museo Municipal de Bellas Artes "Juan B. Castagnino".

Lloyd, R. Impresiones de la República Argentina en el Siglo Veinte. Su historia, gente, comercio, industria y riqueza, Lloyd's Greater Britain Publishing Company LTD, Londres, 1911. Biblioteca Argentina "Juan Álvarez" 